\title{
Lifeworlds under Siege?
}

\author{
A Study of Mediatization as Intrusion and Restraint
}

\author{
ANDRÉ JANSSON
}

There is much ethnographic evidence that media consumption - in the everyday sense of the word is intertwined with most other forms of consumption. Furthermore, all such constellations of consumption are in turn essential for the maintenance of the spatial and temporal structures of subjective and intersubjective lifeworlds. Through media consumption we may reinforce the phenomenological sense of 'here and now', stabilizing the routines and continuity of everyday life. But we may just as well transform ourselves into expansive, transitory timespace travellers, associating and re-associating ourselves with cultural referents far beyond our direct reach. In other words, while the world of media texts confirms and supports the volatility of our senses, the very practices of consumption are significant to our anchorage in socio-physical presence. Media consumption is in itself a process of mediation - the mediation of our own points of view, of ourselves as hermeneutic subjects.

This condition also involves a constant threat of losing control. After all, the world of media texts is alien to us, predominantly built up by industrially produced sign systems. And it is not a sealed world whose entrances we have to search for. It comes to us. It has become more or less omnipresent in our everyday lives. We are constantly within the processes of mediation. Consider the following:

The spaces we live in, in our inner as well as outer worlds, are complicated by the lives we lead and the press of media on our minds and souls. Boundaries are there to be broken. Sounds to be remastered. Images to be refashioned. But meanings are there to be fixed,

School of Arts and Communication, Malmö University, SE 20506 Malmö, andre.jansson@k3.mah.se

\begin{abstract}
accepted, owned, if only for the moment. The press of information, its noise, its intrusion. The endless demands to choose, to dechipher, to discriminate. What do we do with our media and how do we do it? How do we manage? (Silverstone, 1999: 57)
\end{abstract}

What Silverstone is getting at here, is the increasing hermeneutic pressure that the mediatization process has come to put upon the single individual. If the world of media texts may seem like a hermeneutic promise land, where thoughts are liberated and identities negotiated, it may also be regarded as a colonizer, forcing itself upon our very existences notably in the name of 'free speech' and 'free market'. Therefore, Silverstone's last, ethnographically oriented, question is extremely important to raise: How do we manage? And do we really manage?

I am not sure that we do.

In order to bring some more light to this question, this analysis focus upon people's everyday experiences of actually losing control - instances when the coping mechanisms of the lifestyle are no longer enough to handle the intense flow of media texts. When this sense of control is lost the media are no longer considered as a socio-cultural resource, but as a threat to identity creation. This threat involves a disturbance of the balance between symbolic inclusion and exclusion, as well as the interplay between collectivizing and individualizing interpretative acts. In other words, the media flow may be a threat to the maintenance of either subjectivity, or intersubjectivity - or both (Figure 1).

Dividing the analysis into these two aspects, the mediatization process will be discussed in terms of restraints and intrusions. The former analysis illuminates the circumstances under which mediatization is considered as a threat to the possibility of making subjective, individually meaningful lifestyle 
Figure 1. Mediatization as a Threat to Identity Creation

\begin{tabular}{lll} 
Identity aspect & Potential threat & Experience of mediatization \\
\hline Separation/subjectivity & Restraint & (a) Depthlessness \\
Integration/intersubjectivity & (b) Manipulation \\
& Intrusion & (a) Colonization \\
\hline
\end{tabular}

choices. The analysis of intrusions, on the other hand, concerns mediated threats to pre-established interpretative communities, that is, people's sense of belonging and intersubjectivity. It must be stressed here that keeping these two processes apart is primarily an act of theoretical systematization, which simultaneously involves a moment of simplification. Yet, from an analytical perspective it is essential to find a conceptual framework to anchor empirical findings within. Furthermore, as I will argue by the end of this article, this systematization may also work as a point of departure for the development of a moral agenda of audience studies.

\section{The Empirical Study}

The analysis presented here is based on qualitative interview data gathered within the research project Cultural Identities in Transition (CIT), conducted at the Department of Journalism and Mass Communication, University of Göteborg, Sweden. The aim of the project has been to generate a broad understanding of how media consumption expresses and influences people's cultural identities (see also Jansson, 2001b). In this article I have applied two different kinds of data:

Firstly, a total of 41 respondents in the Göteborg region were interviewed about their lifestyles in general and media consumption in particular. The interviews were carried out during 1997-98 on four different locations in the Göteborg area; (1) the inner city, (2) an affluent Western suburb, (3) a Northern working-class suburb, and (4) a countryside village about an hour's ride outside Göteborg. The reason for choosing particular districts was not primarily about enabling comparisons between neighbourhoods - although such comparisons often prove to fruitful. The specific neighbourhoods were not interesting as such. However, starting in different neighbourhoods was a good way to structure the material - due to the segregated character of larger cities like Göteborg. Then, in all districts we gathered respondents of different age, gender and occupation - excluding pensioners and young individuals living with their parents. Primarily we found our respondents by asking friends, and friends of friends.

Secondly, twelve focus group interviews were carried out, designed as reception analyses. The aim was to study how cultural identities were expressed in relation to specific media texts - how people's interpretations and evaluations reflected their cultural belonging and cultural frameworks. Hence, groups of familiar persons (between two and six) were gathered to watch extracts from two different TV programmes. The main reason for choosing respondents that knew each other was that we then could treat them as a kind of interpretative community. However, taking the multiple character of cultural identity as a point of departure, it was theoretically logical to select the groups according to a variety of cultural denominators. Some groups gathered work colleagues, while others brought together organization members, or more informal friends. Whatever their internal relationships were, our objective was to cover as many parts of social space as possible. The interviews started with a presentation, through which the composition of the group was clarified. The groups then watched extracts from two different Swedish TV programmes - the talk-show Renée of the commercial channel TV3 and the arts and culture programme Nike of the Swedish public service system (SVT). While the topic of Renée was 'Charter Tourism', the Nike extract dealt with the artists of the Swedish crystal manufacturer Orrefors. After each programme the respondents were asked about their interpretations of content, form and intentions.

Taken together, these two sources of data are extremely rich. They provide very good insights into how referential frameworks are composed in different groups, and how these groups relate to different kinds of texts and images. The data are especially well suited for clarifying what positions particular media texts hold as cultural referents - insights that can be extended into analyses of the relationships between commercial and public service television, 'information' and 'entertainment', 'high' and 'popular' culture, and so on. As we will see, what is 
a restraint in one context may be an intrusion in another. And such findings, I believe, are not unique for the Swedish cultural context.

\section{Subjectivity}

As argued by Baudrillard (1970/1998) in his essay Personalization or the Smallest Marginal Difference, all kinds of consumption are about the production of difference - a process which is intrinsically bound up with the individual's expressive identity work. To 'personalize' oneself, then, is to create meaningful distinctions through expressive acts, and hopefully having these expressions recognized by the social environment as 'personal'. This is not to say that a 'personalized' kind of consumption is truly unique; what is important from a psychological perspective is that the individual can sustain a sense of individuality stemming from subjectively made lifestyle choices - a sense of controlling the processes of cultural inclusion and exclusion. Accordingly, analyzing the subjective restraints of the mediatization process is a matter of revealing the media system's potential to impose indifference where people actually look for difference.

It can hardly be contested that the world of media texts provides individuals with new outlooks and new lifestyle alternatives. The commercial circulation of media products, through which objects and practices of desire - the means of continuous personalization - are put on display, is the prime vehicle for the contemporary significance of imaginative hedonism (Campbell, 1987). In its entirety, then, the world of media texts may seem like an endless realm of individual choice. There is an endless array of media products to choose between, presenting an indeterminate realm of additional choice.
However, analyzing the CIT material there emerge three major ways in which this pluralistic view can be put into question - three different kinds of restraint regarding the individual's ability to control whether, what, when, where and how to consume (Figure 2). First, people may experience that the amount of consumption alternatives is actually very restricted, too small - either in terms of the media output itself, or in terms of the alternatives presented in the media. In a more theoretical sense, this objection corresponds to a market liberal approach, arguing that increased deregulation of the media system would generate more alternatives. However, since this is not a critique of the mediatization process itself - quite the opposite - I will exclude it from any further analysis.

Second, subjectivity loss may be articulated as a feeling of superficiality or depthlessness - a notion that the media do not actually promote any substantial difference, but merely the illusion of difference. Such arguments have also been raised from Marxist and postmodernist points of view, formulated by theorists such as Kroker (1985), Jameson (1991) and Baudrillard (1970/1998). As the latter puts it in his essay on personalization, 'it is upon the loss of differences that the cult of difference is founded' (Baudrillard, ibid.: 89).

Third, there are respondents who argue that the massive imposition of mediated lifestyle alternatives, as well as media alternatives as such, actually shrinks their room for making independent choices, notably choices of non-consumption. This is the most thoroughgoing critique of the mediatization process, targeting issues of manipulation and false needs. Among Marxist cultural thinkers such as Adorno (1991), Schiller (1969) and Smythe (1981) this line of thought has been prevailing.

Figure 2. The Restraints of Consumer Subjectivity - A Typology of Statements

Media consumption alternatives

Restriction

Depthlessness

Manipulation
The restraint of public service broadcasting, media access problems, etc. make subjectivity problematic.

Commercial format radio, prime time scheduling, spectacularization, etc., make subjectivity illusory/ stereotypic.

Serialization, trailers, entertainment programmes, etc., generate subjectivity loss through addiction.
Mediated consumption alternatives

The media output is too restricted to provide a sufficient amount of alternatives.

Superficial styles, stereotypized role models, sales scheduling, etc., prevent more subjective consumption.

Advertising, TV-shop, the

Internet, etc., create false needs of consumption. 
Analyzing controversial phenomena such as depthlessness and manipulation involves a rather precarious interpretative operation - an act of balance. On the one hand, it is crucial not to underestimate people's stories of everyday life. Most of the critical theorists mentioned above have rejected or overlooked the value of conducting actual ethnographic (or other audience oriented) research, grounding their theses in quite deterministic views of how the mediatization process affects cultural life in general. Indeed, these views are to be reconsidered in light of the situated character of media consumption. On the other hand, people's statements cannot be accepted at face value. They do not provide the researcher with an $\mathrm{x}$-ray into the private lives and minds of individuals. Expressions of restraint (as well as liberation) are thus no proof of any 'objective' operation of 'mediatization', but must be interpreted in light of the overall conditions framing the individual lifestyle. Otherwise, one may easily exaggerate either 'resistance' or 'manipulation'.

\section{(a) Depthlessness}

Turning first to the issue of depthlessness, it is possible to crystallize a couple of sub-themes that are often associated with the mediatization process such as homogenization, spectacularization and fragmentarization. These are typically mentioned by people rich in cultural capital, sustaining a reproductive or progressive ethos, that is, leading ideologically active lifestyles. In their eyes, there is a culturally devastating connection between the ongoing commercialization process and the experience of increased media conformity - notably regarding the TV and radio output. Since these opinions are based on the combination of high cultural preferences and a left-wing political orientation, it is almost 'natural' that they sound like echoes of Marxist cultural critique - as formulated by for example the Frankfurt School (Adorno and Horkheimer, 1944/1979), the Situationist Movement (Debord, 1967/1994), and the political economy approach (Schiller, 1969, 1974; Garnham, 1990). The core argument is that the commercial media system does not fulfil the more specific interests of the audience, but merely provide stereotypic entertainment obeying the logic of audience maximization - the law of the least common cultural denominator (see also Hoskins and Mirus, 1988; Bourdieu, 1998). Above all, these critical respondents experience that their personal right to choose is threatened by standardized formats and pre-fabricated schemata. Sören, the 46-year old musician in the Western suburbs of Göteborg, makes the following statement:

Sören: If I listen to the radio it's almost only P1 [public service 'talk radio']. If I want to hear music, I want to choose it myself. This is in contrast to my daughter who tunes in $N R J$ and thinks it's a pleasure not having to choose. She has both a CD player and a tape recorder that she hardly uses. [...] I panic at Friday night shows on TV, when millions of families are supposed to sit passively and watch a few people being active. That's not natural.

Hence, the general distaste for what may be termed a commercial 'package culture', typically seen in phenomena like charter trips and prepared dinner menus, also includes the formatized programming of commercial radio and television. This result corresponds to what Holt (1998) found in his American study of the influence of cultural capital upon consumption practices, stressing that people with more cultural capital primarily regarded consumer sovereignty as a question of identity and self-actualization. The value of products was estimated in terms of whether they were personally meaningful, rather than according to mere exchange value.

However, against this finding one must object that not even among culturally prestigious respondents is exchange value insignificant as a cultural referent. Quite the opposite: The popularized commercial media output is an essential component for the creation of socio-cultural distinctions. When a respondent like Felicia, the university teacher, states that her preferences are not represented in the flows of commercial broadcasting, and that most advertisers seem to have missed her and her affiliates as a target group, it is not simply a matter of frustration. It is just as much about distanciation and positioning. Probably, it would have been a greater problem to find her favourite cultural products embedded and advertised among the 'avarage' commercial output. Such an experience would have created a sense of cultural dissonance - an identity conflict, based on the devaluation of legitimate cultural capital.

A related kind of dissonance is characteristic for many middle class groupings, striving to appropriate a legitimate stock of cultural capital, adapting their lifestyle practices to their quite recently appropriated positions in socio-physical space. Occupying administrative and managerial jobs and living in their own houses they are to be seen as manifestations of the middle class way of life - grounding 
their social security in material welfare and the creation of a stable family unit in a typically 'safe' suburban area (cf. Silverstone, 1994: 60). In other words, their lifestyles are formed in the juncture between a 'mobility ethos' (cf. Luckmann and Berger, 19xx) and a quest for a happy nuclear family. However, while trying to adapt to the legitimized cultural formula, many people are still not at ease with the cultural competences required from them - especially not since these groups are most often mobile only within the economic sphere of social space. Accordingly, the 'light entertainment' of commercial broadcasting is somewhat pretentiously rejected on the basis of dominant schemes of cultural classification. For example, several of the respondents in suburban middle class settings emphasize that they prefer to watch TV programmes that are in some way 'enriching' to them, that is, cognitively enriching. Watching TV solely for the sake of escaping everyday life, killing time, or relaxing, is not regarded as appropriate behaviour.

Pia: Sometimes it's nice to watch something light... well, not too light then. It should give you something, like a good film or so.

This is where commercial broadcasting becomes a matter of internal conflict. While keeping a classifying distance towards 'too light' entertainment on the personal level, the liberal belief in individual choice and market competition also implies that one cannot judge the taste of others. On the one hand, much of the output of commercial TV are considered as 'uninteresting', 'stupid', 'trashy' etc. (that is depthless); on the other hand, even material of 'low cultural standards' must be accepted if many people consume it. Hence, if others enjoy commercial entertainment, that is up to them. Their tastes are justified through the logic of the marketplace.

Notably, most of these respondents have themselves appropriated commercial television at least technically, through the purchase of a satellite dish. It has become a component of what Silverstone et al. (1992) call the moral economy of the household, and is hence also put on display. The decision is culturally objectified in the dish itself, as is the ideological support of commercial television (see also Brunsdon, 1996; Moores, 1993a: 102-16, 1996). As a cultural referent, then, commercial broadcasting is positively regarded on the institutional level, since competition is seen as a guarantee for increased quality and diversity, but culturally rejected at the actual programming level - a conflict that among the CIT respondents is often expressed through rather contradictory answers. Most nota- bly, this is the case among women with lower education, often spending much time at home with the kids, and whose husbands are in the middle of their careers and are thus the ones professionally sustaining the household's middle class position. These women even express a tendency of hyper-conformity to their liberal values, articulated as an exaggerated will to accept the cultural effects of commercialization - which in turn can be understood as a way of solving the dissonance (cf. Festinger, 1957).

A 34-year-old nurse, whose husband is an engineer, stresses that commercialization has generated far too many channels, and that she and her husband are not interested in watching them because they do not have time for it, and because there is so much 'crap'. At the same time she emphasizes that she is not against commercialization as such, and that TV commercials do not disturb her. In a similar manner another 34-year-old mother, previously working as a laboratory assistant but currently at home with the family's two sons (6 and 8 years), insists that there should not be any more TV channels, especially not because of the kids; 'the children's programmes on TV4 are so violent'. At the same time, however, TV4 is considered as necessary because it induces competition on the TV market. Regarding TV commercials she states on the one hand that 'one must accept it', and on the other hand that TV viewing in the USA (where she has lived for a year) is almost impossible because of all the commercials. The commercialization process is thus supported although it generates feelings of subjectivity restraint, based on depthlessness.

Persons who themselves are professionally involved in the commercial sphere, typically the husbands of the women just described, handle the dissonant experience of commercial broadcasting in a different manner. Instead of just accepting the mechanisms of the market, they put themselves in the producer's position (or, rather, the sales department's), explaining why things are as they are. Topics discussed among these respondents are for example the danger of commercialism turning into monopoly; the different areas in which competition is good; the reasons for why commercial broadcasting does not generate diversity in a small country like Sweden; the circumstances under which advertising can be effective, and so on. Discussions like these reveal a fundamental part of their class identity, in which they are secure of their status - in contrast to the uncertainty regarding the cultural sphere. There is also an additional reason for why these career men do not say very much about their own domestic everyday life experiences: since their work de- 
mands so much of their time, TV and radio consumption is bound to be very limited, mainly restricted to the evening news on TV and sometimes news programmes or music in the car. It can thus be said that although commercial broadcasting is not excluded from their lifeworld, nor is it fully naturalized. A phenomenon like "the disturbing commercial break' does not become a real problem in their dayto-day practices - they are in control.

\section{(b) Manipulation}

This brings me over to the related question of manipulation, which may as well be splintered into a number of sub-themes - such as serialization, addiction and imposition. As many of the CIT respondents argue, the omnipresence of the media in everyday life does not only generate meaningful temporal and spatial structures, in terms of stabilizing routines and rituals. By the same token, the world of media texts continuously - via trailers, adverts, spectacles, and so on - entices individuals to stay longer; to go on consuming, and consuming even more. Among most people there seems to be a general awareness of the various strategies that media producers apply in order to keep up the ratings - an awareness that is sometimes at odds with the creative ethos governing the individual's lifestyle at large.

One typical source of restraint is that everyday life is adapted to media schedules, rather than the other way around. Such experiences are foremost characteristic among people leading expansive lifestyles, striving to broaden the scope of their lifeworlds. In these instances media consumption is not necessarily regarded as something evil or threatening, but rather as a cultural resource providing new outlooks and impulses for the sustenance of particular interests. However, at a certain point media consumption may actually get into conflict with the lifestyle practices it otherwise might have reinforced. Keeping up with the media flow and its schedules, then, is turned into a very time consuming business, fostering frustration rather than inspiration. CIT respondent Helena, a 26-year-old doctoral researcher, even decided to throw the TV set out of her life:

Helena: I had a TV set before... My grandmother died in 1994, whereafter I inherited her gigantic TV set with a big beautiful remote control. And since there is cable TV in the house, I was watching a lot for a couple of years. But since I started working on my PhD and got less time I was really upset with that machine... I thought it stole my time. When I got home at nights I even turned on TV Shop just because it was nice to see something moving, and soaps that I actually didn't like. Then I decided to thrw it out. I gave it to my parents.

CIT: What kinds of things did you feel you didn't have time for?

Helena: Well... doing the dishes and such stupid things... and seeing people instead of just sitting there. [...] I guess I wanted to have more time to meet friends. It's a pretty good excuse too - if it's a good film on TV, I can call a friend nearby and say 'Hey, should I come over to you and we can watch it together?', and then we may chat for a while, and it's all much nicer. $[\ldots]$

CIT: You said you were watching too much... Was it only that you watched too much, or did you also watch things you didn't want too see?

Helena: It was mostly that I watched programmes I didn't like, that didn't give me anything. It might have been Monday night, and I watched Friends on Kanal 5, which I thought was quite a good show, and afterwards came Cybill with Cybill Shepard as an unemployed actress who were upset all the time, really boring... but I didn't turn off, but went on watching Perry Mason, some boring episode I didn't want to see either... Then I realized, 'I don't want to spend my youth this way'.

Compared to the more prestigious groupings discussed above, Helena's mode of consumption shows some important similarities to postmodern lifestyles. She does not actually express any distaste for the commercial, popularized output - although one can notice an underlying notion that these texts are not as meaningful as those of public service media - but is willing to talk about a broad variety of media texts that she likes. Her experience of restraint is not primarily about any presumed depthlessness of for example entertainment shows, but rather about media's capacity to capture her, preventing her from doing things she considers to be her interests. Whether these things really are more interesting to her is impossible to tell from the interview. However, it is obvious that the world of media texts prevented her from identifying directly with the cultural referents that she primarily wants to associate herself with - referents that she wants 
to include in her expressive identity. In this connection it is also important to note how strong a symbolic marker it is not to have a TV. As Helena states, the decision to shut out certain parts of the media flow from her lifeworld has had a great expressive impact upon her social environment - strengthening their belief in her subjectivity, and hence also her sense of identity.

Part of Helena's problem may also be traced to the fact that she lives alone, having the TV set all by herself, and nobody else to talk to most of the time. TV viewing, then, works as a kind of mediated quasi-interaction (Thompson, 1995) - socializing, yet monologic. However, the experience of 'TV addiction' or 'TV enslavement' is also present among several CIT respondents with families. Notably, these individuals stress that family life is largely structured according to TV schedules - which is not only a positive experience. First, it might be frustrating to find that much of the family's time together is spent by the TV set, watching family programmes chosen by the kids. This is not a universal experience, though, but foremost characteristic for those who actively try to restrict family viewing that is, conceptually oriented families, who rather put value in discussions (cf. Lull, 1990).

Second, as for example Carina states, TV viewing might enforce a social split between parents, preventing them from communicating with each other. Carina explains that although both she and her husband like to watch TV when the kids are asleep, it has become a problem that the 'do not talk anymore'. There is simply no time left for discussions. Thus, in both these instances, what seems like social interaction is actually silence, 'just sitting by the set', hindering other choices from being made. I will return to this aspect in the section on intersubjectivity.

In more traditional communities, among persons holding up a strong work ethos, TV viewing is condemned for two basic reasons. On the one hand, as I have mentioned previously, the very practice itself is considered as passive and non-productive. On the other hand, there is a great scepticism as to the intentions and potentials of the content - notably regarding the commercial channels. Many of the rural respondents put pride in the fact that they do not have any other channels than the tree terrestrial ones (SVT1, SVT2 and TV4). Having no access to cable and satellite channels is somehow regarded as a guarantee for not being further indoctrinated and manipulated by commercials and entertainment shows. Especially during the reception analysis of TV3's talkshow Renée several individuals expressed great sus- picion regarding the intention of the programme. In both the orienteering club and the local community club the dominating opinion was that the prime aim of the show was to sell charter trips, and that the entire show was sponsored by travel organizers and caravan producers. Interestingly, some respondents also believed that SVT's arts programme Nike was sponsored by the Swedish crystal producer Orrefors, whose artists were portrayed in the episode. It is quite reasonable to believe that this general scepticism stems from the respondents' great distance from the urban pivots of commercial media production (Renée), on the one hand, and the artistic scene (Nike), on the other. The interview situation clearly catalyzed a striving to reject foreign impulses from entering the lifeworld, and to demonstrate that they were not easily manipulated.

While the general scepticism towards commercialism seems to be strongest among progressive and traditional groupings, it is quite striking to see how widespread the distaste for radio and TV commercials is. This has also been demonstrated through statistical market surveys, comparing people's attitudes towards advertising in different media. Obviously, there is a clear divide between radio and TV advertising on the one hand (negative), and cinema commercials and adverts in the daily press on the other (positive).

Then, why is it all right to encounter adverts in some media, but not in others? Of course, the media channel is not the only determinant for whether advertising is accepted or not; but its characteristics are obviously an essential factor to consider. Seeking the answer in the CIT interviews, one finds at least two major themes. The first one is people's experience that the media via commercials and trailers attempt to make decisions in their place, imposing sales arguments and temptations that are insulting to the individual's sense of subjectivity. This is especially the case when it comes to television and radio, since in these media sophisticated audiovisual techniques are used in order to capture the audience. As Dan, the fireman, puts it:

Dan: Well, I'm not an advertising expert, but you know it's kind of humiliating. Who do they think you are? A complete idiot?

CIT: What kind of advertising do you have in mind?

Dan: When one notices that they are trying to... eeh... they try to pick you up through other things than the product they actually want to advertise. You know, jokes and... Like it was that Hyundai I think it was, that car... 
It was Gert Fylking and Svullo, and he was farting in the car and 'I don't give a damn about nature' he said, and the other guy said like 'Good, I had pea soup for dinner', and then he was farting in the car. That kind of stuff. And then they slipped into, you know, air condition and ventilation and all that... [...] There are so many other things around instead of the product... I think it was Hyundai, but I'm not sure. You can ask almost everyone about that ad and they have seen it and know which one you are talking about. But what did he actually advertise? Which car was it? Yeah... which was it..

Dan's story illuminates that the individual might feel that the media strives to manipulate via 'irrational' arguments - or, rather, no arguments at all. Then, buying something that has been advertised in a 'nonrationalist' manner - which is actually a great deal of today's consumer products (cf. Leiss et. al, 1990/ 1997) - would be a proof of manipulation, and subjectivity loss. Being an essential aspect of the work ethos, this rationalist ideal is strong among many of the CIT respondents, turning the individual away from most phenomena that are not practically functional. There is a clear connection between rationalistic ideals and the belief that advertising makes people buy things they actually do not need. In particular, this weakness is ascribed to other people, like 'trend freaks' and 'commodity people'.

Another side of the scepticism towards TV and radio commercials stems from the experience that these messages restrict one's ability to consume the media programming subjectively, according to free will. Since commercial breaks are embedded in the overall media flow, they are continuously encountered during the overall process of consumption. Hence, the very act of media use is disturbed, manipulated. Regarding television, a quite general finding is that the audience either wants to get rid of these breaks, or, alternatively, wants to perceive the commercial messages according to the same interpretative schemes they apply in relation to the rest of the programming - typically as 'amusement', or 'information'. In other words, they want to approach ads in the mode of consciousness they have indirectly chosen when they decided to take part of the 'primary' media text.

Being in the media text mode (Jansson, 2000) the sudden shift from for example an action film to a series of commercials may come as a shock to the viewer. In Schutz' (1962: 229-34) terms, shifting one's attention from one province of meaning to an- other implies that a new set of interpretative skills must be put into work. The viewer must 'switch off' the generic competences accompanying the action movie, and 'turn on' a kind of advertising mode - which among many individuals incorporates the impulse to change channel or leave the room. Indeed, media producers are continuously trying to minimize the effects of such interpretative shocks, through the creation of smooth audio-visual bridges and new generic formulas for advertising, that is, what Williams (1974) once termed flow programming. Nonetheless, in the CIT material there is no individual who actually speaks of TV commercials as part of the overall event. Rather, commercials are regarded as something outside the TV programming - something that one unfortunately has to "put up with'. The phenomenological experience is thus distinct from the aesthetic-generic form.

This does not imply that the TV audience cannot find the commercials amusing, informative or interesting - or that certain viewers watch them in an artistic mode (cf. Nava and Nava, 1992-171-82). On the contrary, several of the respondents put plenty of interest into discussing commercials, distinguishing between good and bad ones, or otherwise referring to them. There is even an articulated desire for better advertising, which in most cases means spots that are funny and amusing. This desire can be coupled to the dominant connotation of commercial television as a pure entertainment medium (see also Jansson, forthcoming). Viewers ask for a hermeneutic correspondence between programming and advertising - wanting to be amused, rather than persuaded. Hence, in this regard the wish of the audience (or at least a great share of it) coincides with the aims of the producers - who want to keep the viewers pleasantly stuck by their TV screens also during the 'breaks'.

Considering these findings it is also plain to see why people do not criticize adverts in the press and at the movies. In both cases, ads are an integral component of the overall experience. Ads in magazines and newspapers are often mentioned as sources of ideas and impulses - either as a kind of style councils or in the shape of more concrete offers. They are part of the expressive lifestyle package that the magazine provide, or the local information of the newspaper. Moreover, the reader can quite easily skip these ads. In a similar manner, when it comes to cinema commercials, these are positively experienced as a part of the chosen event, marking the gateway to a good time. Then, the sense of being cheated or manipulated is absent - the individual can keep up a sense of subjective control. 


\section{Intersubjectivity}

No identity is the pure correlate of separatedness, or subjectivity. Or, rather, subjectivity can never be uncoupled from the simultaneous operation of intersubjectivity. As outlined in Chapter 3, while the individual maintains a lifeworld that is ultimately unique, formed through personal lived experience, he or she attains confirmation through processes of socialization - the operation of intersubjectivity. One may thus speak of intersubjective lifeworlds in a similar way as interpretative communities. The individual is not part of one single community, but may have certain cultural referents in common with an indefinable number of communities. Furthermore, in practical life it is impossible to discern any finite boundaries or stability regarding such communities. They are merely analytical constructs, abstractions, that the researcher may arrive at via different methods of cultural inquiry (cf. Ortiz, 1997; Jansson, 2001a).

However, from a phenomenological perspective it is of great relevance to investigate which communities people consider themselves as being part of, that is, from which social contexts they attain hermeneutic confirmation and security. And from a media studies perspective it is relevant to find out in what way the media provide people with socializing material - and in what way they threaten preestablished senses of belonging. The following analysis regards the latter aspect, mediatization as intrusion, and discusses two principal types of intersubjectivity loss. The first one is colonization, referring to instances when the media output threatens to take over and break up pre-existing senses of community. The second type is alienation, denoting a more indirect form of intrusion - a situation in which the individual experiences that the media system creates and nurture foreign, and typically unwanted, cultural communities that undermine the position of oneself. Indeed, these two variants are hard to keep apart, and do often co-exist. Yet, as we will see, they articulate different aspects of cultural identity, and in different ways: While the experience of colonization directly points to a threatened community - such as the household unit - the experience of alienation primarily describes who the individual is not, or does not want to be.

\section{(a) Colonization}

The concept of colonization is strongly associated with the social theories of Habermas (1987), describing a society in which the communicative ra- tionality of the lifeworld is threatened by the economic and coercive imperatives of the system. More concretely, the colonization of the lifeworld denotes a pathological form of modernization, in which the power spheres of economy and politics no longer represent people's interests, but merely control people's everyday lives. When studying people's experiences of mass media, it is very interesting to see how both commercial and political pressures enter the lifeworld via the world of media texts - in shape of persuasive market-talk and political paternalism. Furthermore, media themselves are often referred to as colonizers, hindering the processes of social life.

Accordingly, it is primarily the maintenance of the private sphere, the community of the household, that people regard as problematic in times of mediatization. Indeed, as Ritzer (1999) argues, there is hardly no escape from the media anymore - especially not when the logic of the market-place dominates. And due to the introduction of novel media technologies, it is likely to believe that these pressures will continue to grow in the future.

Of course, advertisements and infomercials
pale in comparison to home shopping televi-
sion and the television channels and entire
networks (Home Shopping Network) devoted
to it. Here our homes are invaded around the
clock by slick-talking salespeople, often
joined by celebrities hawking their own
products or those from whose sale they stand
to profit. There is no need to leave home to
purchase: Just telephone and charge (Ritzer,
1999: 149).

The privatization of consumption that Ritzer depicts implies that both the household community and the intersubjectivity of face-to-face market relations are threatened. While the latter condition is hardly mentioned among the CIT respondents partly because neither e-commerce nor home shopping television is a significant component of their everyday lives (at least it was not in 1997-98) there are several examples of 'household intrusions'. For natural reasons, it is primarily respondents with families who mention this problem, and especially those who put reflexive efforts into the modelling of a family ethos. As Lull (1990) found in his extensive analysis of TV viewing in American families, media often works as a transmitter of shared family values, notably from parents to children. These findings are clearly supported by the CIT material. Both tastes and distastes are negotiated via discussions of which media texts are appropriate to 
consume and which are not. Yet, quite often people feel that they are not in control of these intersubjectivity creating processes. Sometimes the relationship between adults is threatened, as we could see in the previous section. In other cases the imperatives of mass media, especially in shape of popular consumption alternatives, enter the household via the children and their friends. One good example is Sören's decision to allow his nine-year-old daughter to watch one soap opera together with him - although the standards of the show is at odds with his progressive ethos - in order not to loose contact with her, and to support her socialization with friends:

Sören: I follow the soap Skilda världar (Different Worlds), together with my daughter. Because that's the only one she is allowed to watch. She told me that everybody else were watching so many soaps, and at first I thought like 'just stop it!'. But she went on arguing and talking about how much all her friends were watching, and that she wanted to see Skilda världar. So we talked about it [...] and then it struck me how silly I was, because such a programme might actually be able to separate me from her! [...] I was quite excited when I got that idea. When watching Skilda världar together it is all about not choosing different worlds. Instead of having different worlds we can have a shared world because we discuss things. It has been rather funny. Of course, sometimes I get very upset with the show, how simplified some matters are presented. But what has been exciting is that one can discuss questions of sex, relationships and moral in relation to something that is not going on within the family.

On the whole, commercial programming directed towards children is met with great scepticism - even among those who support commercial television as such. These programmes, predominantly cartoons, are told to be violent, fragmentary, non-educational and too many. Especially the female respondents in the affluent Western suburbs express great concerns. Tove, a 34-year-old housewife, and her husband have not bought a satellite dish, and are thus deliberately keeping down the family's access to TV channels:

CIT: What's your personal opinion about the changes of Swedish television... more channels, advertising, and so on... although you can only experience it through TV4, since you haven't got cable or dish? Would you like more commercial television?

Tove: No, it's enough. I don't want more, especially not while we have kids. We don't want them to get stuck by the TV set, so it's good if there ain't too much. By the way, I think the children's programmes of TV4 are much worse - more stupid, violent programmes. But my kids don't watch them, because it's the wrong time for them, they are playing instead, which I think is very good. Otherwise, I think it's good to have more channels, since competition is good. You have to put up with the commercials - you do not have to watch them.

Hence, the commercial colonization of family lifeworlds (as described by the respondents) does not occur at random or without resistance. The process is dependent upon a variety of contextual conditions which enable or disable the influence of commercial programming (see also Lull, 1990; Andersson and Jansson, 1997). An interesting side to this problematic, however, is that several of the parents in the CIT material express that the media texts that are popular among the kids - such as Disney and the programmes of SVT - also create a shared representational framework among parents. Children's media texts, whether positively or negatively regarded as cultural referents, contribute to an interpretative community among parents. In other words, these texts do not only contribute to the negotiation of the 'family lifeworld', but also to a kind of 'parental lifeworld' which has an increasingly global, Americanized accent. Even media products that many parents, especially those rich in cultural capital, try to prevent their children from, such as Ninja Turtles and Power Rangers, contribute to the world of family life.

In this context it is also worth mentioning a second community to which media texts are often regarded as an intrusion: the Swedish national community. As several contemporary theorists have argued, the authority of the nation state is successively drained, as the movements of people, capital and information reach increasingly global dimensions (cf. Castells, 1997; Hardt and Negri, 2000). Among the CIT respondents very diverse, as well as ambivalent, experiences of this development flourish. Discussing the influence of foreign media programming activates a variety of seemingly disparate attitudes, such as the individual's views of traditionalism, nationalism, commercialization, popularization, Americanization, and so on. The 
risk of cognitive dissonance is obviously great here. One good example is found among the more conservative groupings in the Western suburbs, who eagerly support both commercialization and Swedish traditions. Thus, watching commercial broadcasting generates mixed feelings, since the output is saturated with 'American trash programmes' - as one of the respondents puts it. Although these individuals argue that British productions attain much 'higher quality', since they are not as spectacular, they also sense a risk that Swedish language and customs are threatened by the massive Anglo-American cultural flow.

Quite interestingly, a similar contradiction can be discerned in the interviews with individuals possessing less economic and cultural capital - individuals who may even be referred to as 'the new underclass' (cf. Lash, 1994). On the one hand, local traditions are given a crucial position. The respondents express about the same worries regarding the expansion of Anglo-American language and symbolic expressions, as do the upper-middle class groupings. On the other hand, living in the low status suburbs of Göteborg, where unemployment rates are high, as are the number of co-existing nationalities, American popular culture tend to work as a unifying factor - a common cultural denominator. According to one of the younger respondents, American TV programmes are much better, simply because the American culture industry has greater resources and longer experience of making good programmes. On the contrary, a barrier is raised against the programming of public service broadcasting, which is not considered as a positive keeper of Swedish traditions, but as an alien, paternalistic force. Above all, it is boring:

CIT: Why don't you watch the programmes of SVT1 and SVT2?

Iris: Haven't you seen the boring programmes? [laughter] Well, it's like "here we are, now we'll try to find out the meaning of stones" or something... I mean, they are so boring... so terribly boring. They could be removed completely.

A similar distaste is expressed regarding daily newspapers, which are considered as 'complicated', 'boring' and 'only black and white'. Thus, in accordance with the dominant connotative pattern, newspapers (tabloids excepted) and public service broadcasting are associated with seriousness and civic duties, while commercial broadcasting stands for spectacle and pleasure. And while seriousness is regarded as the means through which the political system attempts to force people to become responsible citizens, spectacle is seen as the salvation from such obligations. Broadly speaking, as a cultural phenomenon the political world is positioned as an object of anti-identification; a cultural referent one does not associate oneself with. This is a result similar to Morley's (1980) argument in The 'Nationwide' Audience, stressing that persons alienated from the political sphere and other apparatuses of social power refused to make any interpretation of the episode of Nationwide (a current affairs programme of BBC) at all. The cultural framework of the programme was simply not the concern of their world, and 'failed to live up to their standards of "good TV" defined in terms of enjoyment and entertainment' (Morley, 1992: 114-5; see also Sparks, 1988).

In these groups, then, spectacle becomes the desired mode of representation - a mode in which representation and content are merged into one. However, arguing that the spectacle of commercial television (whatever such a generalization may refer to) is totally deprived of meaning, that form invades content, following theorists like Baudrillard and Debord, would be a harsh theoretical exaggeration, ignoring the hermeneutic praxis of the audience. Since there are readings, there are also meanings in the texts, or, rather, potential meanings that are activated and shaped through the reading process. This is the obvious reason for why politically alienated groups actually turn to commercial broadcasting. It provides texts and narratives that can be read without the risk of causing threats to their sense of sustaining a somehow alternative community - since spectacles are not interpreted as extensions of uncontrollable politico-administrative systems. On the contrary, the spectacles of commercial broadcasting represent an alternative representational world, relieved from the abstract institutional pressures surrounding the socio-physical realm of lived experience (cf. Giddens, 1991: 126-39).

\section{(b) Alienation}

In several of the above contexts it is also appropriate to speak of alienation, as people experience that media texts foster the establishment and reproduction of interpretative communities that are hermeneutically foreign. While the suburban women refer to the political-administrative apparatuses, as well as to sub-cultural phenomena such as graffiti and 'gang-culcture', which they do not approve of, other groups attain other objects of estrangement. It all depends upon how the individual positions him- 
self or herself, and what position in physical and social space he or she strains to appropriate. From a sociological perspective, however, there are two interrelated phenomena that are especially important to consider - 'city culture' and 'popular culture'.

Among the rural CIT respondents local community still holds a strong grip over identity. Most of the individuals are born in the same region, and passes on the traditions and values of earlier generations to their own children. Against this backdrop it is understandable that media texts like the local newspaper, local public service radio and television, and the particular community paper (containing ads, announcements and short articles about local events) are put at the very centre of cultural practice. These channels constitute the very opposites of most other media output. Notably, what they present is a less urban perspective of everyday life - although both local radio and regional television emanate from nearby urban areas. There is a strong scepticism towards national broadcasting, which is regarded as biased in favour of Stockholm, as well as most commercial alternatives, which are targeting city people, as well as distributing alien images of city life. Especially during the reception interviews in the rural district, it becomes clear that many people think that their way of life is not represented in the dominant media flow.

However, this is of course not a simple function of where individuals live; there are a number of socializing factors at play, shaping the ethos of single individuals. For example, as previous studies have shown, commercial city radio holds a strong position among young people living outside larger cities (Andersson, 1998). Listening to these channels is a way for the younger generation to get access to the city culture, while not yet being socio-physically part of it. City news and pop music create a sense of familiarity, a shared cultural horizon. And, reasonably, this condition further increases the experiences of alienation among older people, noting various more or less debased cultural expressions and attributes flourishing in their close environment.

A corresponding attitude can be noted among individuals with cultural tastes that are commonly referred to as 'highbrow' - that is, individuals in possession of the modern forms of cultural capital discussed by Bourdieu (1979/1984) and others (cf. Holt, 1998). In an era where borders are transcended and distinctions blurred, when the opposition between highbrow and lowbrow is seemingly substituted by a vaguely differentiating regime of 'nobrow' culture (Seabrook, 2000), people's aims of making distinctions, positioning themselves in social space, are problematized. In general, the cultural transformation of the media system is described as a process of popularization - a turn towards entertainment and fiction. On the one hand, most of these respondents are careful not to judge the tastes of others too categorically, or boasting too much about their own cultural skills. Everyone has the right to make individual choices. On the other hand, one can note a considerable distance, even a sense of alienation, in relation to the expanding field of popular culture. This ambivalence characterizes the following citation of two middle-aged women, both positioned in privileged social settings, discussing the arts programme Nike:

CIT: What kind of genre would you say this is? Do you make any associations to other programmes?

R1: I would say it holds the same standards as Musikfrågan [a quiz show about classical music on SVT], it has a quite narrow audience. [...] Those who buy paintings with, and now I sounds awfully snobbish, the man with the rain-hat and the pipe, or the crying child, probably don't watch this programme... Now I was rude [laughter].

CIT: Is this an important genre? Is it an important programme?

R1: Yes, I think so. Why shouldn't those who keep this interest have their interests satisfied as well?

$R 2$ : We have to satisfy all people, or all levels. Just as much as we think this is a good programme, all pieces must have the right to... $R 2$ : Who would otherwise buy this art!? The crystal art?

R1: Perhaps people do anyway, but... but we have to, and that's the advantage with TV, that we have all the pieces. We have everything from charter to this, and that's a contrast. And I think both have the right to exist.

Obviously, while keeping up a very tolerant, democratic, facade, the modern cultural hierarchy prevails underneath - making distinctions between cultural products as well as people in terms of 'levels'. In addition (which is revealed elsewhere in the interview - and in several other interviews), these distinctions do not only regard the classification of products, but also the ways in which products are consumed. Consuming media texts in a 'distracted' and 'passive' mode is almost regarded as an expression of illiteracy, generating fragmentary and depthless cultural experiences. In particular, young 
people's inability to be concentrated is mentioned in a tone of cultural worry - perhaps articulating a more timeless conflict between generations.

However, in the extension of this condition emerges a new, potential problem - the postmodern problem of vanishing distinctions. In this context it is interesting to note that the above-mentioned programme Nike cannot actually be regarded as a 'traditionally' highbrow cultural programme. Both to its form and content it transcends earlier conventions of high and low, mixing topics such as pop/ rock music and Hollywood movies with architecture, painting and theatre, and adopting quite innovative audio-visual techniques. The latter condition is obviously something that viewers notice; the approach is commented by several of the CIT respondents. For example, a group of younger university students suggest that this seemingly 'popularized' audio-visual form (which they say they enjoy) actually makes the programme less accessible among older people, who they think would prefer a lower pulse. However, at least in this particular case, it seems like age is not a very important factor, compared to symbolic, or rather, artistic, experience in general. Among the respondents who can be regarded as rich in cultural capital Nike's combination of form and content is considered as 'beautiful', 'relieving' and 'classy' - in other words, essential to the artistic experience. A group of textile artists argue that the quite innovative form is part of the concept, expressing a thorough artistic ambition. What may look like popularization, then, is conceived of as the very opposite - experimentation. It is close at hand to explain these descriptions of Nike as a function of the programme's pre-established cultural calssification. Since the cultural referent Nike - a well-known SVT programme since the early $1990 \mathrm{~s}$ - is associated with both class and innovation, crossing the border to popular culture is also about class and innovation. There is a basic semiotic logic to this process.

Accordingly, on behalf of the cultural consumers, the media audience, it is problematic to speak of vanishing distinctions, or 'nobrow'. The space of cultural classifications is continuously remodelled, and although new forms of expressions may problematize predominant categories the threat of cultural alienation is commonly compensated for through the establishment of new distinctions. Among the highbrow audience the prevalence of aesthetic postmodernization seems to be a quite marginal threat to intersubjectivity. A more signifi- cant source of alienation is the expanding appropriation of genuinely lowbrow culture - whatever that is.

\section{Concluding Remarks: Problematizing the Good Life}

As I have tried to illuminate in this article, people continuously have to handle the omnipresence of mediated messages - sometimes maintaining a sense of control, sometimes losing it. Any clear-cut answer to the question of whether mediatization is about liberation or exploitation is impossible to give. The lingering answer is the ongoing struggle and negotiation between inclusion and exclusion people's endeavour to manage the processes of mediation, using them as meaningful resources for the maintenance of lifeworlds and life biographies. The experience of being in control, through routines, plans and intersubjective understandings, is a fluctuating matter, related to individual ambitions and ideals, as well as the overarching fluidity of physical, social and representational life circumstances. There is nothing stable here.

Accordingly, what these findings have shown, is how articulations of media intrusions and restraints are also articulations of cultural identity - articulations of people's conceptions of themselves and the communities they want to be part of. The more intense the processes of mediatization get, the more people's lifestyles become a matter of positioning themselves in relation to the media flow. And losing control of it is almost like losing a piece of oneself.

In extension, the results of this study actualize the need for a revitalized discussion of life quality and identity politics within audience studies. On the one hand, people's discomforts and frustrations with the media flow, as well as their enjoyments and enrichments, articulate their social positions. On the other hand, since most people struggle with the media in one way or another, issues of the good life cannot be addressed simply in terms of social power. Many of the current debates regarding the media's tendency to reinforce social stratification, in terms of 'tastes' and 'preferences' (see Jansson, 2002), could be complemented with a more fundamental problematization of psycho-social well-being. I believe that the systematized view of identity threats outlined in this article - depthlessness, manipulation, colonization and alienation - is a fruitful starting point for such a problematization. 


\section{Note}

1. TV4 - the terrestrial commercial TV channel in Sweden - is partly an exception, since it is not allowed to include commercials in the middle of programmes, but only between programmes. Other Swedish channels, like TV3 and Kanal 5, are broadcasted from London via satellite, and thus not bound to Swedish advertising regulations.

\section{Bibliography}

Adorno, Theodor (1991) The Culture Industry: Selected Essays on Mass Culture. London: Routledge.

Adorno, Theodor and Max Horkheimer (1944/1979) Dialectic of Enlightenment. London: Verso.

Andersson, Magnus (1998) En handling vanligare än andra: Några ord om de människor som lyssnar på radio. Göteborg: Department of Journalism and Mass Communication, unpublished paper.

Andersson, Magnus and André Jansson (1997) Media Use and Cultural Identity: Results and Reflections from an Interview Study in Two Different Parts of Gothenburg. Paper presented at The $13^{\text {th }}$ Nordic Conference in Mass Communication Research, August 9-12 1997, Jyväskylä, Finland.

Baudrillard, Jean (1970/1998) The Consumer Society: Myths and Structures. London: Routledge.

Bourdieu, Pierre (1979/1984) Distinction: A Social Critique of the Judgement of Taste. London: Routledge.

Bourdieu, Pierre (1998) On Television and Journalism. London: Pluto Press.

Brunsdon, Charlotte (1996) 'Satellite Dishes and the Landscape of Taste', in Hay, James; Lawrence Grossberg and Ellen Wartella (eds.) Audience and its Landscape. Boulder: Westview Press.

Campbell, Colin (1987) The Romanthic Ethic and the spirit of Modern Consumerism. Oxford: Basil Blackwell.

Castells, Manuel (1997) The Power of Identity (The Information Age: Economy, Society and Culture. Volume II). Oxford: Blackwell.

Debord, Guy (1967/1994) The Society of the Spectacle. New York: Zone Books.

Festinger, Leon (1957) A Theory of Cognitive Dissonance. Stanford: Stanford University Press.

Garnham, Nicholas (1990) Capitalism and Communication. London: Sage.

Giddens, Anthony (1991) Modernity and Self-Identity: Self and Society in the Late Modern Age. Cambridge: Polity Press.

Habermas, Jürgen (1987) The Theory of Communicative Action: Volume Two: Lifeworld and System: A Critique of Functionalist Reason. Boston: Beacon Press.

Hardt, Michael and Antonio Negri (2000) Empire. Boston: Harvard University Press.
Holt, Douglas B. (1998) 'Does Cultural Capital Structure American Consumption?', Journal of Consumer Research, Vol. 25, No. 3: 1-25.

Hoskins, Colin och Ralf Mirus (1988) 'Reasons for the US Dominance of the International Trade in Television Programmes', Media, Culture and Society, Vol. 10: 499-515.

Jameson, Fredric (1991) Postmodernism, or, the Cultural Logic of Late Capitalism. Durham: Duke University Press.

Jansson, André (2000) 'A Matter of Attitude: Reflections on Phenomenology and Media Culture', Nordicom Review, Vol. 21, No. 2: 227-41.

Jansson, André (2001a) 'Contested Meanings: Audience Studies and the Concept of Cultural Identity', in Kivikuru, Ullamaija (ed.) Contesting the Frontiers: Media and Dimensions of Identity. Göteborg: Nordicom.

Jansson, André (2001b) Image Culture: Media, Consumption and Everyday Life in Reflexive Modernity. Göteborg: Dept. of Journalism and Mass Communication, Göteborg University.

Jansson, André (2002) 'Coping with the Pleasure Machine: Commercial Broadcasting and the Politics of Cultural Identity', in Johansson, Thomas and Ove Sernhede (eds) Lifestyle, Desire and Politics: Contemporary Identities. Göteborg: Daidalos.

Kroker, Arthur (1985) 'Television and the Triumph of Culture: Three Theses', Canadian Journal of Political and Social Theory, Vol. 9, No. 3: 37-47.

Lash, Scott and John Urry (1994) Economies of Signs and Space. London: Sage.

Leiss, William; Stephen Kline and Sut Jhally (1990/ 1997) Social Communication in Advertising: Persons, Products and Images of Well Being. London: Routledge.

Liebes, Tamar and Elihu Katz (1990) The Export of Meaning: Cross-Cultural Readings of Dallas. New York: Oxford University Press.

Luckmann, Thomas and Peter L. Berger (1964) 'Social Mobility and Personal Identity', Archives Européennes de Sociologie, Vol. 5, No. 2: 331 44.

Lull, James (1990) Inside Family Viewing. Ethnographic Research on Television's Audiences. London: Routledge.

Moores, Shaun (1993) Interpreting Audiences. The Ethnography of Media Consumption. London: Sage.

Moores, Shaun (1996) Satellite Television and Everyday Life. Articulating Technology. Luton: University of Luton Press.

Morley, David (1980) The 'Nationwide' Audience. Structure and Decoding. London: British Film Institute.

Morley, David (1992) Television, Audiences and Cultural Studies. London: Routledge. 
Nava, Mica (1992) Changing Cultures: Feminism, Youth and Consumerism. London: Sage.

Ortiz, Renato (1997) 'World Modernities and Identity', Media Development, Vol. 44, No. 2: 37-40.

Ritzer, George (1999) Enchanting a Disenchanted World: Revolutionizing the Means of Consumption. Thousand Oaks: Pine Forge Press.

Schiller, Herbert I. (1969) Mass Communication and the American Empire. New York: Augustus M Kelly.

Schutz, Alfred (1962) Collected Papers I: The Problem of Social Reality. The Hague: Martinus Nijhoff.

Seabrook, John (2000) Nobrow: The Culture of Marketing the Marketing of Culture. London: Methuen.

Silverstone, Roger (1994) Television and Everyday Life. London: Routledge.

Silverstone, Roger (1999) Why Study the Media? London: Sage.

Silverstone, Roger; Eric Hirsch and David Morley (1992) 'Information and Communication Technologies and the Moral Economy of the Household', in Silverstone, Roger and Eric Hirsch (eds.) Consuming Technologies: Media and Information in Domestic Spaces. London: Routledge.

Smythe, Dallas (1981) Dependency Road: Communications, Capitalism, Consciousness, and Canada. Norwood: Ablex.

Somers, Margaret R. and Gloria D. Gibson (1994) 'Reclaiming the Epistemological "Other": Narrative and the Social Construction of Identity', in Calhoun, Craig (ed.) Social Theory and the Politics of Identity. Oxford: Blackwell.

Sparks, Colin (1988) 'The Popular Press and Political Democracy', Media, Culture and Society, Vol. 10, No. 2: 209-23.

Thompson, John B. (1995) The Media and Modernity: A Social Theory of the Media. Cambridge: Polity.

Williams, Raymond (1974) Television: Technology and Cultural Form. London: Fontana. 